\section{ARENDT Y EL NUEVO IMPERIALISMO}

\author{
Sonia Arribas \\ Investigadora ICREA \\ Departamento de Humanidades \\ Universidad Pompeu Fabra-Barcelona
}

\section{ARENDT AND THE NEW IMPERIALISM}

\begin{abstract}
In this article I firstly reconstruct the main theses of the first chapter of the second part of The Origins of Totalitarianism: "The political emancipation of the bourgeoisie". Arendt argues here that imperialism at the end of the $19^{\text {th }}$ and the beginning of the $20^{\text {th }}$ centuries was the consequence of two conflicting logics: that of the geographically bounded nation-state, and that of the unlimited expansion of the capitalist economy. Secondly, I show how this idea of two conflicting logics has been recently taken over by different social analysts to investigate the world geopolitical and economic situation during the presidential mandate of George Bush Jr. -a period that David Harvey has once again called, like the thirty year period investigated by Arendt, "the new imperialism".
\end{abstract}

KEY WORDS: Arendt; imperialism; capital; Rosa Luxembourg; David Harvey; Retort; George Bush Jr.

En la que es seguramente la revista más leída (y mejor escrita) sobre crítica de libros, la London Review of Books, apareció en el 2007 un artículo sobre varios libros que habían sido publicados con ocasión del centenario del nacimiento de Hannah Arendt (Robin, 2007). El artículo tenía una doble intención: dibujar un mapa de los temas más recurrentes del expansivo universo académico de los estudios arendtianos, y señalar aquéllos que, a juicio del autor, habían quedado desde su concepción, y siguen quedándose en la actualidad, y de una forma sintomática, en los márgenes. Los temas que se han venido repitiendo hasta la saciedad giran en su mayor parte en torno a la teoría arendtiana del totalitarismo. Según Robin, se trata de ideas promovidas por los numerosos y acérrimos defensores de la política norteamericana en versión Guerra Fría o Eje del Mal, y en forma de armazón teórico con el que representar la psicología social del enemigo: sea el del pasado reciente -la Alemania Nazi-, o la Unión Soviética y el resto de países comunistas, hasta, por supuesto, nuestros días -Al-Qaida, Hamas o la Jihad islámica-. A estos ultraliberales cabría añadir los no menos aguerridos seguidores
RESUMEN: Se reconstruyen en primer lugar las tesis centrales que aparecen en el primer capitulo "La emancipación política de la burguesía" de la segunda parte de los Orígenes del Totalitarismo. Arendt argumenta aquí que el imperialismo de finales del siglo XIX y principios del siglo XX fue la consecuencia de dos lógicas en conflicto: la del estado-nación europeo, acotada a un emplazamiento geográfico, y la de la expansión ilimitada de la economía capitalista. En segundo lugar, se expone cómo esta idea de las dos lógicas en conflicto ha sido retomada recientemente por diversos analistas sociales para investigar la coyuntura geopolítica y económica mundial coincidente con el periodo de mandato presidencial de George Bush Jr., -un período que David Harvey ha venido a redominar, como ya se llamó el lapso de treinta años investigado por Arendt, "el nuevo imperialismo".

PALABRAS CLAVE: Arendt; imperialismo; capital; Rosa Luxemburgo; David Harvey; Retort; George Bush Jr.

del liberalismo (político y/o económico) que emergieron en la Francia post-68 desde posiciones radicales de izquierda en la juventud, transformados en la madurez, y sin solución de continuidad, en la vanguardia e intelligentsia del acomodaticio centrismo y del conservadurismo europeos'.

Entrar en el porqué de este uso ad nauseam de ciertas tesis de Arendt por parte de determinados sectores políticos no es lo que me ocupará aquí: mi objetivo será, por el contrario, el de volver a uno de esos temas fundamentales de Arendt que se han ido significativamente dejando a un lado, aquél que tiene que ver con los formidables estudios que la filósofa le dedicó al imperialismo². Ellos no sólo trastocan y cuestionan las fáciles aplicaciones habituales de la tesis totalitarista, sino que además, como trataré de mostrar, nos proporcionan un utensilio teórico muy necesario para entender el mundo contemporáneo. De forma particular, y para desarrollar esta idea, quisiera concentrarme en la apropiación que de estos análisis han llevado a cabo recientemente un reducido pero influyente número de politólogos, economistas y colectivos para 
investigar la coyuntura geopolítica y económica mundial desde el comienzo del nuevo siglo. Creo, no obstante, y aunque sólo se percibirá de manera indirecta, que esta lectura estará respondiendo de algún modo al cómo es que ciertos planteamientos filosóficos, en este caso la teoría del totalitarismo de Arendt, han ganado la batalla hegemónica de las ideas en un momento histórico muy determinado: las fuerzas triunfantes de toda coyuntura geopolítica y económica, y en particular de la que aquí quedará reflejada, necesitan siempre un marco ideológico con el que expresarse. Así es desde luego como interpreta el propio Corey Robin el éxito académico, e intelectual en general, de la teoría arendtiana del totalitarismo ${ }^{3}$.

\section{Dos lógicas en CONFLICTO: EL ESTAdO-NACiÓN Y LA EXPANSIÓN CAPITALISTA}

Las tesis sobre el imperialismo que aparecen en el primer capítulo "La emancipación política de la burguesía" de la segunda parte de Los Orígenes del Totalitarismo se pueden reducir, sin entrar en los abundantes pormenores históricos que acompañan la narrativa de Arendt, a una serie de rasgos caracteristicos. Estos elementos teóricos son los que conforman el marco conceptual que ha sido retomado en la actualidad por un grupo importante de economistas y analistas políticos para delimitar el campo de fuerzas (económicas, geopolíticas, etc.) desde el que vislumbrar la escena internacional contemporánea. Hannah Arendt toma como período álgido del imperialismo el que tuvo lugar en las tres décadas que transcurren entre 1884 y 1914, aquél en el que la burguesía adquirió una gran preeminencia económica, que no quedó traducida, no obstante, en un fuerte dominio político. Según Arendt, en ese período convulsivo de la historia mundial el estado-nación y sus instituciones se terminaron por establecer como el centro neurálgico de las decisiones políticas, pero también, y simultáneamente, como el marco desde el que se tenían que emplazar las operaciones capitalistas de la burguesía. Este cruce entre los límites territoriales del estado-nación, en buena medida necesitados de un emplazamiento fijo, y las operaciones expansivas e ilimitadas de la economía burguesa capitalista generó un conflicto que sólo se pudo solventar mediante la salida hacia el exterior -más allá de las fronteras estatales- del funcionamiento económico del capital (y del encuadre político, según los países en juego).
De ahí que la característica fundamental de la combinación imperialismo y estado-nación fuera justamente su inagotable necesidad de expansión en términos geográficos y monetarios, pero también en términos de movimientos de población. Esta combinación, históricamente nueva de finales del siglo XIX, tuvo su razón de ser, según Arendt, en la especulación empresarial capitalista: es decir, en el siempre infinito crecimiento promovido por el desarrollo de la producción tecnológico-industrial y las transacciones económicas.

En el estado-nación europeo del siglo XIX, sostiene Arendt, se había constituido una clase dominante, la burguesa, que paulatinamente se fue encontrando con que los límites nacionales de sus mismo nacimiento le imponían una barrera infranqueable a la expansión económica, necesitada siempre de nuevos territorios, más fuerza de trabajo, un creciente suministro de materias primas, y mercados cada vez más amplios para el intercambio de mercancías. Tal situación le forzó la salida hacia fuera de las fronteras nacionales, a la exportación del sistema económico. El objetivo era poder alcanzar el ritmo de crecimiento impuesto por las demandas capitalistas. El auge de una política verdaderamente a escala mundial (lo que hoy llamariamos "globalización") provino de la superación de los límites territoriales que se habian ido consolidando desde dos siglos antes aproximadamente, es decir, como consecuencia no sólo de la expansión económica a marchas forzadas, sino también de la exportación, según los casos, de ciertas instituciones políticas a los nuevos territorios conquistados.

Pero la expansión característica del imperialismo estuvo lastrada en su mismo ser por una tensión interna. Arendt utiliza el término "contradicción" para dar cuenta de esta tensión. Toma la idea de los análisis de Marx sobre la naturaleza necesariamente contradictoria del capitalismo ${ }^{4}$, aunque sin desarrollarla por completo, pues en su caso está únicamente dirigida al estudio histórico del imperialismo: según Arendt, en medio de ese afán expansivo del imperialismo, se daba una contradicción (o disimetría) entre la estructura política (y jurídica, habría que añadir) desde la que se establecian y funcionaban las operaciones industriales y financieras de la clase burguesa (es decir, el estado-nación) y la expansión económica requerida por el imperativo capitalista de la productividad y el crecimiento por el crecimiento mismo: "A diferencia de la estructura económica, la estructura política no puede ser expandida 
indefinidamente, porque no está basada en la productividad del hombre, la cual es, por supuesto, ilimitada. De todas las formas de gobierno y organizaciones del pueblo, el estado-nación es el menos apropiado para el crecimiento ilimitado porque el consenso genuino que está a su base no puede ser estirado indefinidamente y sólo se puede conseguir raramente, y con dificultades, en los pueblos conquistados" (Arendt, 1976, 126) Más aún, mientras que el estado-nación estaba configurado desde sus inicios y en su mayor parte por la identidad de un pueblo y por instituciones estatales afincadas en un territorio, los requerimientos expansivos de la economía capitalista, su misma necesidad interna de acaparamiento y acumulación de valor, desbarataban sin piedad los límites jurídico-políticos que delimitaban el emplazamiento local de partida. Esta tensión interna al imperialismo permite explicar, por ejemplo, que el modelo del imperialismo francés tuviera un éxito mucho menor que el británico. El imperialismo francés persiguió la difusión bajo una única bandera, la suya, y en algunos casos incluso intentó la creación de la estructura de un cuerpo político colonial en los territorios conquistados que pudiera servir a los intereses del estado-nación francés. En cierto modo se podría argumentar que su proceder era un resquicio de la lógica de la exportación del imperio -de cierta estructura política estable, parecida formalmente al estado-nación-. El modelo británico, por el contrario, el que podríamos caracterizar como propiamente imperialista, separó por completo las instituciones nacionales en casa de la administración colonial en los territorios bajo su dominio (que pasaron a llamarse Commonwealth), aun cuando las primeras ejercieron un fuerte control sobre los segundos, y con el objetivo último de que la expansión económica no se encontrase con los límites provenientes de la configuración de cuerpos políticos estables (y dibujados en gran medida a semejanza del estado-nación).

Esta fundamental diferencia tuvo su razón de ser, a juicio de Arendt, en el hecho de que imperialismo y construcción de un imperio son, desde una perspectiva histórica, fenómenos muy diferentes. $Y$ es que no es lo mismo un proceso de expansión por la expansión misma, y la conquista político-militar para obtener territorios, materias primas y productos. La diferencia que se da entre ambos reside en que mientras que el imperio y la conquista se proponen trasladar las instituciones de la nación a los territorios bajo su dominio y en su conjunto, en el imperialismo y la expansión las instituciones nacionales per- manecen drásticamente separadas de la administración colonial, incluso cuando las primeras no cesan de ejercer un control férreo sobre las segundas. Es decir, el imperialismo persigue la expansión del poder político, pero sin el fundamento de un cuerpo político. En los términos de Marx, se podría diferenciar, a muy grandes rasgos, entre el imperio en tanto que formación social precapitalista, y el imperialismo como formación social propiamente capitalista. Esta diferenciación también le permite denunciar a Arendt los errores de cierta historiografía contemporánea que confunde los conceptos de imperio y de imperialismo con la intención de suavizar estética e ideológicamente los efectos del imperialismo a escala global: "los historiadores contemporáneos, confrontados con el espectáculo de unos pocos capitalistas conduciendo sus búsquedas predatorias de nuevas inversiones... visten el imperialismo con la antigua grandeza de Roma y de Alejandro el Grande, una grandeza que haria más humanamente tolerable lo que estaba ocurriendo" (Arendt, 1976, 132).

La denuncia que hace Arendt a la asimilación del concepto de imperio con el de imperialismo tiene también relevancia en la situación geopolítica contemporánea. Siguiendo la propuesta conceptual de Arendt, se podrían muy bien interpretar y criticar, por ejemplo, las tesis centrales que el politólogo Herfried Münkler defiende en un libro con bastante éxito de ventas actualmente en Alemania sobre la historia y lógica del imperio desde una perspectiva de sociología comparativa (Münkler, 2005). El argumento teórico del libro se basa en la idea de que es posible hallar las coordenadas periódicas de la lógica de un modelo transhistórico de imperio - una especie de tipo ideal de imperio reconocible a través de sus distintas encarnaciones históricas-. A grandes rasgos, Münkler argumenta que ya se trate del imperium romanum, del imperio español de los Habsburgo, o los Estados Unidos desde finales del siglo XIX, todo imperio se establece y mantiene (y finalmente es llevado a la desintegración) en la esfera de la dominación mundial predominantemente mediante la intervención militar y política. Su declive cierra un ciclo civilizatorio y hegemónico y es la consecuencia de la pérdida de ese poderío militar y político, de la competencia a muerte y la guerra con nuevas fuerzas emergentes. Pues bien, al no llevar a cabo una distinción conceptual entre la noción de imperio precapitalista y la del imperialismo capitalista, este análisis no presta atención a la creciente importancia, podría argumentarse que a partir del siglo XV, 
pero ya de forma intensiva a partir del predominio holandés en el siglo XVII, de los movimientos transnacionales de flujos de capital, así como las actividades mercantiles que operan en un nivel distinto del estado-nación, y cuya naturaleza necesariamente trasciende las fronteras nacionales. Es decir, la lógica imperialista -especialmente la que derivó de la crisis interna del capitalismo de finales del siglo XIXproviene no tanto o primariamente de la rivalidad interestatal (o inter-imperios) basada en la dominación geopolítica y militar, sino de la competencia económica entre agentes privados y en un mercado cada vez más universal $-y$, no conviene olvidarlo, en una relación tensional con la lógica territorial y/o configuración del estado-nación. Y, lo que es tan importante, la lectura de Münkler tampoco da cuenta de la enorme variación en el nexo producido por las estrategias capitalistas del estado-nación y la lógica territorial: ha habido estados que han otorgado independencia jurídica a los territorios bajo su dominio, también múltiples situaciones intermedias de semi-dependencia, hasta por supuesto el control directo del territorio y la población en la búsqueda de Lebensraum ${ }^{5}$.

De hecho, según Arendt, la diferencia que se da entre el imperialismo y el imperio también se traduce en el plano económico: es decir, una cosa es el comercio y la conquista marítima en pro del comercio (propios del imperio), otra muy distinta la expansión por la expansión misma (caracteristica fundamental del imperialismo). El primero no genera la susodicha contradicción entre la estructura estable del estado-nación y las necesidades del comercio (y Arendt argumenta al respecto que se puede exportar el nacionalismo sin que vaya en detrimento del imperio) y el segundo, por el contrario, sí que genera la contradicción. De nuevo, Arendt compara al respecto el caso del imperialismo británico, cuyo rasgo fundamental consistió en el hecho de que no intentó exportar su idea de nación y sus instituciones democráticas a los territorios donde alcanzaba, con el método francés, que se caracterizó por sus desastrosos intentos de combinar la aspiración nacional en los países 0 zonas receptoras (por ejemplo, Argelia) con la construcción de un imperio. Sus coordenadas básicas no hallaron su plasmación principal en la expansión y especulación capitalistas, sino en la exportación de ciertas ideas y prácticas características del estado-nación. Esta exportación de lo político, también explica, según Arendt, el que la rebelión nacional por parte de las colonias francesas frente al estado francés tuviera un cariz muy distinto, vinculado a un cuerpo político de base, del de las luchas por la independencia provenientes de las sometidas al dominio británico.

La expansión imperialista proviene en primer término de una crisis económica por la cual la producción del capital y la emergencia de dinero "superfluo", el resultado de una especie de ahorro excesivo, ya no encuentra una inversión productiva y rentable dentro de las fronteras nacionales y tiene que salir a otras geografías para lograrla. El imperialismo persigue, en principio, que las leyes del capitalismo por sí solas penetren la nueva realidad, recreándola para ofrecer los materiales necesarios para la creación ilimitada de más dinero, de capital. Y sólo de una forma complementaria o subsidiaria aparece cierta forma de estructura política para facilitar esa expansión ilimitada. Así surge, sostiene Arendt, la idea de un poder político ilimitado y sin otro fin que ser concebido como la estructura que dé forma a ese afán expansivo. Pero esta estructura es en sí misma contradictoria puesto que el cuerpo político tiende a la estabilidad y a la fijación institucional y jurídica en un territorio y población nacionales, mientras que la expansión tiende a la desestabilización continua pues consiste en un torrente eterno de cambios que arrasa con todas las formas políticas.

No es de extrañar en este sentido que el Leviathan de Hobbes ejemplifique para Arendt la filosofía política que ya en el siglo XVII anticiparía y encarnaría esta contradicción interna al imperialismo (Hobbes, 1985). Hobbes representó filosóficamente la práctica efectiva, constatada por la teoría del imperialismo de Arendt, de que la acumulación de poder deriva en última instancia del beneficio propio, del interés egoista, de la búsqueda de riqueza y el bien privado. El poder es el control que permite al individuo burgués, desde una posición de aislamiento, mirar por sí mismo fijando los precios y regulando la demanda y la oferta. $Y$ la esfera política no es un fin en sí mismo sino tan sólo el medio para conseguir la seguridad y el orden donde lograr el objetivo del beneficio individual. A estos fines, logrados precariamente, subyace un estado de guerra permanente, de lucha de todos contra todos. La inestabilidad inherente a la comunidad política tan sólo se subsana, en tal estado de cosas, mediante el constante crecimiento del poder político. Sólo un poder político ilimitado, así lee Arendt a Hobbes, consigue estar a la altura del insaciable deseo de la acumulación capitalista, del incansable acaparamiento de propiedad y capital, de la especulación sin límites. 
Hay otro factor que Arendt considera extremadamente relevante a la hora de delimitar la lógica del imperialismo: junto a la exportación del capital inherente a la expansión productiva, la enorme riqueza (y la pobre redistribución que la acompaña), el imperialismo se hace posible mediante "una acumulación original de capital". Este concepto lo toma Arendt de El Capital de Marx (Marx, 2000b, 197259), así como de los estudios de Rosa Luxemburgo sobre la acumulación de capital y el imperialismo (Luxemburg, 2003). Consiste en una repetición de la apropiación del capital, por parte de la burguesía, a partir del robo y del expolio de otros lugares de la tierra y como consecuencia de las necesidades expansivas de la acumulación por la acumulación misma. Arendt trae a colación en este sentido diversos tipos de métodos fraudulentos que se practicaron en numerosos lugares del planeta (Panamá, Sudáfrica, etc.) para la obtención de capital y la futura consecución de beneficios. Los dueños de riqueza superflua perseguian en un primer término la expansión por la expansión misma, sin someter a sus empresas a ningún tipo de control político y jurídico "en una orgía sin paralelo de estafas, escándalos financieros y especulación en la bolsa, tanto más alarmante cuanto que las inversiones en el extranjero crecían mucho más rápidamente que las domésticas" (Arendt, 1976, 149). Sólo en un segundo momento, cuando las empresas llevaban más tiempo funcionando en un determinado lugar, sólo entonces se buscaba el amparo de las instituciones políticas y la reglamentación jurídica, pero exclusivamente como un instrumento de protección de la propiedad privada recién adquirida mediante el expolio y la destrucción.

La explicación de Arendt sigue al pie de la letra las magistrales páginas de Marx en el primer volumen de $E I$ Capital dedicadas al "secreto de la acumulación originaria". En Marx, la acumulación originaria se distingue por dos aspectos paralelos: por un lado, tiene la función de mito para la ideología burguesa y para la economía política en tanto que punto de partida previo a -y fundador dela acumulación capitalista: "Esta acumulación originaria desempeña en la economía política aproximadamente el mismo papel que el pecado original en la teología" (Marx, $2000 b$, 197). En un pasado remoto -así reza el mito- hubo determinados individuos o grupos que se hicieron con una gran cantidad de riqueza gracias a su laboriosidad y su capacidad ahorrativa, y a diferencia de la ociosidad y holgazanería de aquéllos que pasaban el tiempo sin hacer nada. Éstos son los que hoy carecen de propiedades. Pero, por otro lado, desde la perspectiva de la crítica de la economía política, se vislumbra que este mito ha ser invertido porque esconde un secreto: no es más que la justificación de una situación presente en la que se constata que mientras que hay individuos que sin trabajar acumulan riqueza sin cesar, otros no poseen otra cosa que su propia fuerza de trabajo, su propia vida, porque han sido desposeídos de todo lo demás. En otras palabras, el mito que desde la perspectiva de la economía política se remonta a un pasado imaginado para justificar en términos del mérito de cada cual las injusticias actuales, lo desmonta la crítica de la economía política como una práctica presente y real de reproducción de desigualdad e injusticia, de expolio, violencia y robos silenciados, convertidos en secretos: "en la historia real desempeñan un gran papel la conquista, la esclavización, el robo y el asesinato, en una palabra, la violencia. En la dulce economía política, por el contrario, reinó desde siempre el idilio [...] En realidad, los medios de la acumulación originaria son cualquier cosa menos idilicos" (Marx, 2000b, 198).

Por su parte, Rosa Luxemburgo apunta, desarrollando las intuiciones de Marx, que el fenómeno de la acumulación originaria tiene lugar no sólo en los primeros momentos de la formación y consolidación del sistema de producción capitalista, sino en todas y cada una de las fases históricas de acumulación de capital (Luxemburg, 2003, 434). Juega un papel importante en las primeras etapas del capitalismo europeo, cuando las fuerzas emergentes se lanzaban a la conquista del nuevo mundo, de países productores de materias primas como la India. Pero también tiene lugar acumulación originaria en tanto que una forma de sujeción de las colonias en los siglos posteriores mediante la paulatina destrucción de las organizaciones político-sociales de las sociedades primitivas y la concomitante apropiación de sus medios de producción, la introducción forzosa del comercio de mercancías y la conversión de los nativos en un proletariado colonial forzado a trabajar sin remedio por un salario. Todo esto, señala también Luxemburgo, viene siempre acompañado de un fuerte militarismo mediante el cual se fuerza la apropiación originaria en las zonas no capitalistas, esto es, su progresiva transformación al capitalismo: "El imperialismo es la expresión política de la acumulación de capital en su lucha competitiva por lo que todavía permanece abierto en el entorno no capitalista" (Luxemburg, 2003, 426). El imperialismo se expande me- 
diante la extorsión, la falta de ley, la violencia y la agresión continua frente al mundo no capitalista.

Como resumen, la lógica expansiva del imperialismo, según Arendt, consiste en tres rasgos esenciales: (1) se sostiene bajo la forma del conflicto entre la configuración estable de las instituciones jurídico-políticas y territoriales, por un lado, y la lógica de la acumulación capitalista, por otro; (2) la contradicción inherente entre estas dos lógicas sólo se resuelve mediante la expansión geográfica; y (3) a la base de esta expansión geográfica tiene lugar una acumulación originaria de capital, tal y como Marx concibió este proceso.

\section{Otros antecedentes de la teoría del imperialismo de ARendt}

El periodo investigado por Arendt, el que transcurre entre el último cuarto del siglo XIX y la Primera Guerra Mundial, y con protagonistas a las grandes potencias europeas en su brutal competencia por materias y mercados, recibe comúnmente el nombre de "nuevo imperialismo". En 1898 apareció ya un artículo de Charles A. Conant, "The Economic Basis of Imperialism", en el que se exponía que el imperialismo era el proceso que se derivaba de la necesidad de absorción del capital excedente en un momento de crisis doméstica y falta de salidas a la inversión ${ }^{6}$. Según esta descripción, el conflicto de las grandes potencias en distintos lugares del mundo, asociado a la emergencia del capitalismo monopolista, era de un calibre muy distinto -de ahí el adjetivo de "nuevo"- que el colonialismo que le precedió. En los análisis del clásico de 1902 Imperialism: A Study (Hobson, 2006), sobre el imperialismo británico, se acentuaba asimismo que la mejora de los métodos de producción y la concentración de la propiedad y el control iban necesariamente de la mano de una tendencia imperialista. A medida que las naciones europeas iban adoptando métodos industriales avanzados, se les hacia más y más difícil encontrar los mercados para dar salida a los recursos económicos excesivos y al capital excedente. La capacidad de crecimiento y de producción dentro de los paises superaba la posibilidad de consumo, de manera que en el mercado sobraba tanto dinero como faltaban espacios donde invertirlo con rentabilidad. El otro gran referente del imperialismo es el libro de Lenin, El Impe- rialismo, fase superior del capitalismo (Lenin, 1948) ${ }^{7}$, publicado originariamente en 1916, y donde se ofrece un análisis de cómo la transición del capitalismo liberal al capitalismo monopolista definió no sólo el pasaje al imperialismo salvaje, sino también a la grave situación de rivalidad inter-imperialista que finalmente concluyó en la Primera Guerra Mundial. El capitalismo monopolista significó una etapa nueva, más allá del capitalismo competitivo de mediados de siglo, porque en él el capital financiero se asentó mediante una alianza entre las grandes empresas y el capital bancario que acabó imponiéndose a los estados mismos. Y la concentración y la centralización del capital que este proceso acarreó llevaron asimismo consigo una explotación nunca vista de la periferia.

Lo que los anteriores análisis resaltaron fue el hecho de que el imperialismo, especialmente el británico de finales del siglo XIX, fuese una consecuencia directa de la expansión comercial resultante de una crisis y de una transformación económica a gran escala. Si Gran Bretaña acompañó sus necesidades expansivas de una política militar, lo hizo primariamente como consecuencia de los imperativos económicos, y no como un fin en sí mismo de dominación político-militar. Así se explica, por ejemplo, la enorme influencia que ejerció en Sudamérica, el que tratase de establecer, con la ayuda de su dominio marítimo, tratados comerciales y relaciones financieras con los territorios de ultramar. Aunque el sometimiento de la periferia a la metrópoli no fue total (es decir, era técnicamente hablando "informal") y se mantenía la separación entre ambas, sí que se producía una dependencia en el plano económico, consecuencia de las necesidades expansivas del capital británico.

Hannah Arendt toma estas conclusiones en sus análisis sobre el imperialismo y se sitúa por tanto en una línea muy próxima a las tesis marxistas, en el sentido, ya citado, de su diferenciación con respecto a la noción de imperio y el énfasis que pone en el proceso histórico, afectado por las formas políticas, de la expansión económica. El sistema de producción capitalista atravesó distintas etapas de desarrollo y la etapa del monopolio fue la que creó las condiciones para la expansión imperialista, ayudada de fuerzas militares y de dominio político. El imperialismo no tuvo sólo lugar (ni lo sigue teniendo hoy día) principalmente mediante los actos de los estados-naciones en su lucha por la hegemonía, sino mediante las acciones de las corpora- 
ciones, los agentes privados, y los mecanismos internacionales de intercambio, finanzas e inversiones y, eso sí, de la mano de un poder político y jurídico que los acompaña y los da forma, que los ayuda jurídica y militarmente, y con los que está constitutivamente en conflicto.

\section{El nUeVo imperialismo Según DaVid Harvey}

¿Por qué se están interesando en la actualidad diversos politólogos, sociólogos y economistas en las tesis de Hannah Arendt sobre el imperialismo? Si nos retrotraemos unos 20 años, no es difícil constatar que hacia finales del siglo $X X$, y en particular después de la caída del muro de Berlín, se estaba dando una situación en el plano internacional que a primera vista parecía bastante favorable. A grandes rasgos, este período se caracterizó por: (1) la OTAN se afianzaba como única fuerza mayor tras la descomposición de la URSS; (2) se daba cierto renacer económico de especulaciones explosivas tras un lapso de 25 años de declive financiero; (3) Europa se situaba cómodamente en el ámbito de influencia atlántico; (4) se iniciaba una sinergia con China, que suplía mano de obra y mercancias baratas; (5) en el plano militar, la ONU hacía la vista gorda frente a los pequeños excesos de EEUU, y se montaban iniciativas de intervención en otros países, violando la Carta de la ONU, con el deseo y la voluntad de que estas excepciones servirian al objetivo de la consecución de la democracia en el futuro. Pues bien, esta situación queda rota de una forma manifiesta con el ataque terrorista a las Torres Gemelas, la Ilegada de George Bush Jr. al poder, la "guerra contra el terror" y la posterior invasión de Irak. Los analistas que vuelven a Hannah Arendt encuentran en su teoría los elementos teóricos desde los que conceptualizar esta ruptura, así como la constelación política, geoestratégica y económica que se ha derivado de ella.

En el primero de los libros que nos ocupa, denomina David Harvey "imperialismo capitalista" a una fusión contradictoria entre la política del estado y la del imperio (Harvey, 2005). Por falta de espacio, me limitaré a exponer los puntos teóricos en los que el autor remite a los análisis de Hannah Arendt sobre el imperialismo. Por un lado, el imperialismo se define como un proyecto político de ocupación y organización de territorios con fines políticos, económicos y militares, y conlleva estrategias de distinto tipo a nivel mundial. Por otro lado, la lógica de acumulación consiste en procesos moleculares de acumulación de capital en el espacio y el tiempo, a través de distintos territorios, y mediante las prácticas de la producción, el intercambio, el comercio, los flujos de capital, la migración del trabajo, la transferencia de tecnología, la especulación monetaria, los flujos de información, de cultura, etc. Se trata, por consiguiente, de dos lógicas distintas puesto que tienen motivaciones distintas: la del capital busca la acumulación (la expansión por la expansión misma en Arendt), la de la política persigue principalmente el aumento del poder estatal con respecto a otros estados. La del capital opera en un espacio y tiempo ilimitados, mientras que la política opera en un territorio y por un tiempo determinado [Aparte del trabajo de Arendt, Harvey también cita el monumental libro de Giovanni Arrighi sobre las distintas épocas del desarrollo capitalista desde sus orígenes hace 700 años. Las dos lógicas reciben aquí los nombres de "territorial" y "capitalista" (Arrighi, 1994)].

Según Harvey, la lógica política y la capitalista pueden atravesar momentos de gran antagonismo. Para el caso que Harvey estudia, esto significa que no se puede interpretar la invasión de Irak simplemente como funcional con respecto a los requisitos de la acumulación del capital. La relación entre ambas tiene que interpretarse dialécticamente: esto es, ni funcionalmente con respecto a la acumulación del capital, ni unilateralmente con respecto al dominio político, militar y geoestratégico. Ahora bien, según el momento histórico-geográfico, lo que sí que ocurre es que una de las dos lógicas puede dominar a la otra. Lo característico del imperialismo es que la lógica propiamente capitalista domina -aunque puede haber momentos, dentro de un período histórico imperialista, en que predomine la lógica territorial-. Si la lógica de acumulación y expansión capitalista es de naturaleza ilimitada en lo temporal y espacial, la pregunta que se plantea Harvey es la misma que ya se hiciera Arendt: ¿Cómo puede responder la lógica territorial, limitada a un territorio estatal, a la lógica infinita de la acumulación capitalista, de naturaleza ilimitada? Y Arendt misma le proporciona la respuesta: "una acumulación sin fin de propiedad debe basarse en una acumulación sin fin de poder. El proceso de la acumulación ilimitada de capital necesita la estructura política de un 'poder tan ilimitado' que pueda proteger la propiedad creciente al hacerse constantemente más poderoso" (Arendt, 1976, 143\%; también citado en Harvey, 2005, 34). En un período imperialista hay

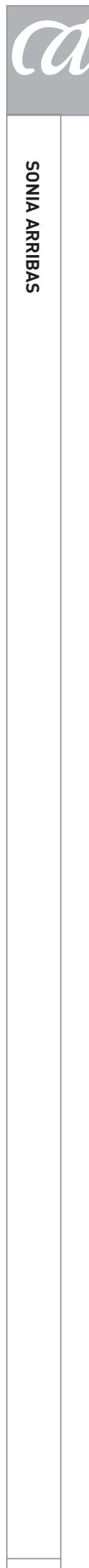

ARBOR CLXXXVI 742 marzo-abril [2010] 265-276 ISSN: 0210-1963 
un estado hegemónico que necesita mantener su posición en relación a la acumulación de capital y que necesita extender, expandir y intensificar su poder político -lo que es perfectamente legible, según Harvey, en la política exterior de los Estados Unidos desde los años 1990.

La otra pregunta que se hace Harvey es si los Estados Unidos tienen hoy el suficiente poder estratégico y de recursos, el suficiente poder político, para efectivamente ser ese dirigente o administrador a escala global de la acumulación ilimitada de capital. Es decir, a nivel internacional, Harvey se cuestiona por un lado si tienen los Estados Unidos la suficiente fuerza militar y política para mantener el consenso internacional de los países afectados, involucrados o de los observadores ${ }^{9}$. $Y$ en el plano doméstico, Harvey investiga por otro lado cómo se asienta y legitima actualmente el poder político en Estados Unidos. Aquí de nuevo echa mano de los análisis de Arendt sobre el imperialismo, también de los que aparecen en el capítulo 5 de la segunda parte, para señalar que, en efecto, se puede producir una suspensión de la lucha de clases interna mediante la construcción de una alianza entre lo que Arendt denomina "the mob" (el populacho) y el capital dentro del estado-nación ${ }^{10}$.

Harvey también actualiza el concepto marxiano de la acumulación originaria y denomina "acumulación por desposesión" al fenómeno por el cual se deja en la intemperie absoluta a grupos enteros de población que en un momento dado no logran incorporarse plenamente al mercado de trabajo, y se quedan como un ejército de reserva industrial para ser utilizados cuando el momento lo requiera. Según Harvey, el capitalismo necesita un otro, una especie de afuera con el que alimentarse cuando le resulte necesario. 0 bien un otro exterior que ya está ahí, un entorno no capitalista (otro país, pero también domésticamente: la educación, la sanidad por ejemplo), u otro que se puede manufacturar activamente. $Y$, de nuevo en este segundo caso, la referencia es Arendt, en este caso los análisis que la filósofa le dedicó a las depresiones de 1860 y 1870 en Gran Bretaña, que transformaron una economía capitalista basada en la producción a una economía de especulación financiera.

Harvey traslada esos mismos análisis al neoliberalismo y movimientos especulativos en gran escala durante los años 80 y 90 . Como hemos visto, según Arendt el proceso de la acumulación original es la fuerza constante en el imperialismo que crea al tiempo que necesita tierras vacías, nuevos recursos materiales, más fuerza de trabajo. ¿Cómo se traduce esta acumulación por desposesión en situación global actual? Los fenómenos que cita Harvey son, entre otros: la mercantilización y privatización de la tierra, la expulsión a la fuerza de la población campesina, la conversión de derechos de propiedad (comunes, colectivos, estatales, etc.) en derechos de propiedad privada exclusiva, la mercantilización de la fuerza de trabajo y la supresión de formas alternativas (indigenas) de producción y consumo, la monetarización del cambio y los impuestos, la creciente deuda nacional, y el sistema de créditos $^{11}$.

\section{Un COLECtivo frente al IMPERIALISMO: Retort}

El colectivo Retort, afincado en la bahía de San Francisco, está formado por 40 personas provenientes de distintas esferas: entre ellas hay activistas, académicos, artistas, etc. y ha sido uno de los más activos en las manifestaciones contra la política exterior norteamericana durante el mandato de George Bush. El lema con el que salió a la calle fue: "Ni su guerra ni su paz"12. Para Retort el concepto de acumulación primitiva u originaria, tomado de Marx vía Arendt, es el utensilio teórico básico para explicar la prolongada vida del capitalismo: no consiste en un fenómeno del pasado, sino en un proceso incompleto y recurrente, que está actualmente teniendo lugar y que ellos hacen remontar a la Doctrina Monroe de 1823, es decir, a la primera formulación política de la independencia norteamericana en lo que se refiere a su política exterior.

La acumulación originaria se sigue dando no sólo porque la clase de los pequeños trabajadores propietarios de tierra haya sido bastante resistente al capitalismo, y sigue hoy en el siglo XXI luchando por su supervivencia, también porque el colapso de los "socialismos realmente existentes" produjo unos cientos de millones de nuevos campesinos. Si la acumulación depende de la multiplicación del proletariado "verdadero", los últimos 30 años -y contra la opinión predominante que sostiene que el proletariado como tal ha desaparecido- son testigos de que nunca terminan de desaparecer los obstáculos para la creación de esta uniformidad (Retort, 2005, 75). Y tam- 
bién porque la desposesión de los trabajadores no es la única forma de acumulación primitiva. La desposesión se puede dar a nieveles muy distintos, como decia Arendt: "el pecado original del simple robo debe ser repetido para que el motor de la acumulación no se ralentice" (Retort, 2005, 76). De ahí los movimientos periódicos del capitalismo hacia fuera, hacia geografías y zonas que pueda saquear sin oposición (Esa falta de resistencia es la que se esperaba en el caso de Irak). Pero del mismo modo también se explica su impulso hacia dentro, hacia la profundidad de la fábrica de lo social, en búsqueda de más y más recursos que privatizar (pensiones, viviendas, bosques, etc.). En los mismos términos explica asimismo Retort la devaluación a gran escala de la riqueza, la permanente transferencia a través de las fronteras y hacia el exterior de los recursos locales $^{13}$.

Pero Retort también se pregunta por qué este proceso de acumulación primitiva necesita regularmente una forma imperialista militar, por qué tiene que ir de la mano de todos los recursos militares del estado. Las razones por las que un estado se decide por la acción militar suelen ser pocas veces puramente económicas: se trata de razones económicas y también "espectaculares" y geopolíticas. Para el caso de la invasión de Irak, los Estados Unidos no actuaron pensando que el petróleo ya es un bien escaso en el momento presente, sino que están anticipando el momento en que se llegue en el futuro a la mayor cota de extracción y a partir de ahí haya que ir disminuyendo las cantidades que se van extrayendo. Es decir, lo que subyace a la decisión no es una razón meramente económica (aunque también lo sea), sino una cuestión estratégica y geopolítica. Esta multiplicidad de factores se anudan en la idea de "guerra permanente", cuya conceptualización básica toman de la lectura arendtiana de Hobbes y del mismo modo que ya lo hiciera David Harvey: "El proceso ilimitado de la acumulación de capital necesita la estructura política de un 'poder tan ilimitado' que puede proteger la propiedad creciente haciéndose cada vez más poderoso" (Arendt, 1976, 143). La guerra no es un fenómeno excepcional a los procesos de modernización capitalista, sino un fenómeno consustancial a ellos, especialmente durante los últimos 200 años, desde que Estados Unidos se convirtió en hegemónico después de que la guerra de 1812 acabó con los designios británicos en el Atlántico norte. La guerra irá en aumento hasta la futura consecución de un estado de guerra permanente.

\section{El imperialismo hOY: LAS teSIS de ARENDT eN LA ENCRUCIJADA DE LOS DEBATES CONTEMPORÁNEOS}

Lo que está en juego en los libros analizados es cómo interpretar la etapa de Bush Jr. en el poder no sólo en tanto que una etapa imperialista caracterizada por una fuerte alianza de lo militar y lo expansivo y de unilateralismo -reflejados en el ataque a Afganistán y la invasión de Irak-, sino también como un episodio sintomático dentro de un proceso mucho más largo de hegemonía norteamericana y de turbulencias económicas domésticas con repercusiones a escala global (El factor principal dentro de estas turbulencias está siendo, de forma cada vez alarmante, la creciente deuda). En ellos se ponen asimismo sobre el tapete una serie de utensilios teóricos, aprendidos de Arendt (y de Marx), y manejados dialécticamente para abordar la coyuntura mundial actual atendiendo simultáneamente a factores económicos, geopolíticos y militares. Ahora bien, aun siguiendo a grandes rasgos los parámetros de Arendt, las lecturas, interpretaciones o predicciones que se siguen en cada caso pueden ser divergentes (tanto si se investiga la política exterior norteamericana, como si lo que se estudian son otros casos más locales de expansión acumulativa del capital):

1) Retort considera que la etapa de Bush Jr. se ha tratado de una etapa más del desarrollo capitalista, el cual tiene como centro neurálgico de momento, hasta la posible ascensión de China o la India, a los Estados Unidos. Sería, por consiguiente, una etapa más de una guerra permanente capitalista, eso sí, con ciertas etapas más militaristas y otras menos, pero cada vez más necesitada del dominio espectacular, geoestratégico y mediático.

2) Se podría interpretar, no obstante, que la necesaria conexión que establece Retort entre la lógica expansiva del capitalismo y la de la guerra es demasiado forzada. Se están dando casos de expansión por expansión misma, de acumulación originaria -el tsunami inmobiliario, a escala mundial por ejemplo- sin uso de violencia explícita.

3) También se podría considerar con Harvey, y siguiendo a Gramsci, si lo que está en juego en el imperialismo actual son etapas del capitalismo en las que prevalece o bien la fuerza/la violencia, o bien el consenso. Esta

ARBOR CLXXXVI 742 marzo-abril [2010] 265-276 ISSN: 0210-1963 
consideración podria llevar a hacer distinciones en términos de qué estados favorecen una u otra medida, y establecer así los parámetros de coordinación o conflicto que se dan en las relaciones interestatales. Aún más, cabría asimismo conjeturar si cuando se llega a la violencia extrema se pueden transformar incluso las coordenadas mismas del estado burgués y su sistema de libertades, de tal forma que deje ya de serlo y se convierta en otra cosa (Así se ha interpretado desde muchos frentes la "Patriot Act" norteamericana). Es decir, se trataría de articular la dialéctica siempre en transformación entre el desarrollo a largo plazo de la expansión capitalista y las relaciones inter-estatales.

4) Pero también se puede pensar, como lo hacen Toni Negri y Michael Hardt (Hardt y Negri, 2001, 221-239) y en este caso a diferencia de Hannah Arendt, que hemos entrado en una etapa del capitalismo en que ya no se puede hablar tanto de estados soberanos, de una lógica que se pueda definir en lo puramente territorial, sino más bien de una lógica de expansión que ha arrasado con la etapa del imperialismo (el cual requería en su misma definición, como hemos visto, el conflicto entre lo expansivo y lo territorial). En este sentido, es interesante traer a colación un editorial en el diario británico "The Guardian" escrito por Hardt, justamente cuando empezaba la invasión de Irak, y en la que argumentaba que Bush se estaba alejando de la lógica del capital que tan efectivamente habia desempeñado Bill Clinton, -y que Hardt veía como la lógica natural a nuestro período histórico (Hardt, 2002)-. Las críticas a la lectura del imperio de Negri y Hardt han sido múltiples y aquí no puedo entrar a analizarlas ${ }^{14}$.

6) En cualquier caso, los estudios sobre el imperialismo de Hannah Arendt ponen claramente de manifiesto que un capitalismo ajeno a las fricciones violentas entre estados, o violentas con respecto a los territorios sometidos a los efectos de la expansión capitalista, nunca ha tenido lugar por completo. Viendo el poco éxito de la invasión de Irak, parece que este tipo de operaciones bélicas se van a convertir en un riesgo demasiado alto de asumir en el futuro. Sin embargo, los líderes del partido demócrata, victorioso en las elecciones al congreso del pasado mes de noviembre, tampoco están mostrando ningún tipo de interés en cambiar los parámetros básicos de esta lógica que desgraciadamente desde hace más de un siglo nos acompaña (Brenner, 2007) (Davis, 2007).

\section{NOTAS}

1 Ya van saliendo libros muy valiosos sobre la historia política y cultural de este período que llega hasta nuestros dias. Sobre la historia del liberalismo francés antitotalitario (Christofferson, 2004) y sobre el acomodaticio papel del centro liberal internacional de finales del siglo $X X$, el siempre magnífico (Anderson, 2005). Sobre el uso político contemporáneo del antitotalitarismo: (Zizek, 2002).

2 Me limitaré a las tesis centrales del capitulo 5 de la segunda parte: "La emancipación política de la burguesía" (Arendt, 1976). Véase también el artículo de Hannah Arendt que encabeza este monográfico: "Estado nacional y democracia".

3 Corey Robin señala varios fallos graves en la teoría arendtiana del totalitarismo, aquéllos que han dado pie a su éxito en el plano hegemónico. Sin temor a simplificarla, se podrian resumir en lo siguiente: la rapidez con la que ensambla como fenómenos homólogos racismo y marxismo, Auschwitz y Gulag, fascismo y comunismo. En Arendt, la crisis del estado nación y su organización interna en forma de clases conllevan la extinción de la identidad individual y su concomitante subsunción en organizaciones que, bajo la bandera de la naturaleza (nazismo) o de la historia
Recibido: 23 de agosto de 2007

Aceptado: 15 de febrero de 2009 
(estalinismo) reducen al individuo a la animalidad más básica. Robin subraya la pobreza conceptual de estos análisis en lo que se refiere a la falta de una paciente toma en consideración de los factores políticos, económicos y de poder específicos de cada caso, desaparecidos todos bajo el manto del común denominador de la anomia desértica del totalitarismo. También recuerda el comentario que el crítico Irving Howe hizo sobre la tesis arendtiana del totalitarismo hacia finales de la Guerra Fría, el que tuvo que realizar en su defensa frente a los ataques a los que fue sometida por los historiadores: se trata, según Irving Howe, de una intuición metafísica, una ficción límite e imaginativa, más próxima a la especulación filosófica que al análisis histórico y político riguroso.

4 En Marx la contradicción del sistema de producción ya se encuentra in nuce en la mercancía entre los dos polos de la forma del valor, los que posteriormente se desarrollan a medida que esta forma también se va desarrollando en sus sucesivas encarnaciones (Marx, 2000a).

5 Una magnífica crítica de este libro es (Teschke, 2006) donde aparte de subrayar lo que significa eliminar al estilo de Münkler el análisis marxista de la lógica imperialista, es decir, la crítica al imperialismo como fuente de genocidios, racismo, guerra permanente, desplazamientos de masas de población, epidemias, etc., -nada de lo cual aparece en el libro en cuestión-, se hace también una pequeña biografía de la bastante típica trayectoria intelectual y académica del politólogo alemán, desde una posición marxista en la juventud, hasta esta supuestamente neutral descripción de la transhistoricidad de la lógica del imperio que no puede acabar siendo sino una rehabilitación del concepto y las prácticas del imperio.

6 Tomo esta referencia de (Foster, 2002).

7 Hannah Arendt critica la idea de que el imperialismo se trate de la "última" etapa del capitalismo en referencia a Lenin sin darse cuenta de que Lenin quería más bien decir la etapa más desarrollada del capitalismo, es decir, la etapa monopolista: (Arendt, 1976, 138).

8 De ahí deriva, según Arendt, la ideología del progreso de finales del s. XIX que presagió el nacimiento del imperialismo -y cuya crítica Arendt toma de Walter Benjamin (Mate, 2006).

9 El aparato teórico proviene en este caso de: (Gramsci, 2001).

10 En estos términos, por ejemplo, interpreta Tom Mertes el voto del proletariado norteamericano en la segunda victoria de George Bush en el 2004 (Mertes, 2004) consecuencia inmediata de la falta de alternativas ofrecidas por la izquierda demócrata tras el progresivo desmantelamiento, también en el período Clinton, de los últimos resquicios del "New Deal". El éxito republicano en el logro del voto de la clase trabajadora más pudiente mediante la fórmula ideológica de la defensa de los valores familiares se consiguió en un entorno (el de los estados sureños de los Estados Unidos) fragmentado e individualizado al máximo y dispuesto a aferrarse a formas de afiliación no relacionadas con la clase: la familia patriarcal, el nacionalismo militarista y el fundamentalismo protestante (Brenner, 2007, 46-49).

11 Para una critica al sistema de microcréditos y el proletariado informal desde la perspectiva de la crítica marxista a la "acumulación originaria": (Davis, 2004).
12 Entre los más conocidos del grupo se encuentran el historiador del arte T. J. Clark y el crítico literario e estudioso de la literatura comparada Franco Moretti. El colectivo ha participado recientemente con una exposición sobre la guerra en Irak en la II Bienal de Arte Contemporáneo de Sevilla, cuyo lema ha sido la frase de Benjamin de que "la tradición de los oprimidos nos enseña que el estado de emergencia en el que vivimos es la regla, no la excepción. Debemos llegar a un concepto de la historia que corresponda a esta verdad": http://www.fundacionbiacs.com/site_es/index.htm

13 El mejor ejemplo de "acumulación original de capital", a la que estamos ya muy habituados en nuestro país, es comprar una tierra por prácticamente nada a un agricultor que no consigue salir adelante, lograr por influencias varias (inclusive sobornos) que esa tierra sea recalificada como urbanizable, y luego revenderla: capital en estado puro: D-M-D (dineromercancía-dinero). La lógica de la acumulación original no necesita ir acompañada de violencia explícita.

14 Por ejemplo: (Meiksins Wood, 2003) y (Aronowitz y Balakrishnan, 2003).

\section{BIBLIOGRAFÍA}

Anderson, Perry (2005): Spectrum. From Right to Left in the World of Ideas, Londres y Nueva York, Verso.

Arendt, Hannah (1976): The Origins of Totalitarianism, Londres y Nueva York, Harvest, Harcourt Brace \& Company.

Aronowitz, Stanley y Balakrishnan, Gomal (2003): Debating Empire, Londres, Verso.

Arrighi, Giovanni (1994): The Long Twentieth Century. Money, Power, and the Origins of Our Times, Londres, Verso. 
Brenner, Robert (2007): "Structure vs. Conjuncture. The 2006 Elections and the Rightward Shift", New Left Review 43, enero-febrero, 2007, pp. 33-59.

Christopherson, Michael Scott (2004): French Intellectuals Against the Left: The Antitotalitarian Movement of the 1970s, Nueva York y Oxford, Berghahn Books.

Davis, Mike (2004): "Planet of Slums", New Left Review 26, marzo-abril, 2004, pp. 5-34.

- (2007): "The Democrats after November", New Left Review 43, enerofebrero, 2007, pp. 5-31.

Foster, John Bellamy (2002): "The Rediscovery of Imperialism", Monthly Review vol. 54, n. 6 : http://www.monthlyreview.org/1102jbf.htm

Gramsci, Antonio (2001): Cuadernos de la cárcel, ed. Valentino Gerratana, trad. Ana María Palos y rev. José Luis González, México, Ediciones ERA-Universidad Autónoma de Puebla, 2001.

Hardt, Michael y Negri, Toni (2001): Empire, Cambridge y Londres, Harvard University Press.
Hardt, Michael (2002): "Folly of our masters of the universe", The Guardian, 18 diciembre, 2002: http://www.guardian. co.uk/comment/story/0,861942,00. $\mathrm{html}$

Harvey, David (2005): The New Imperialism, Nueva York, Oxford University Press.

Hobbes, Thomas (1985): Leviathan, Londres, Penguin Classics.

Hobson, John A. (2006): Imperialism: A Study, Nueva York, Cosimo Classics.

Lenin, V. I. (1948): El imperialismo, fase superior del capitalismo, Obras Escogidas de Lenin, Moscú, Ediciones en Lenguas Extranjeras: http://www.monografias. com/trabajos15/el-imperialismo/elimperialismo.shtml

Luxembourg, Rosa (2003): The Accumulation of Capital, trans. Agnes Schwarzschild, Londres y Nueva York, Routledge.

Mate, Reyes (2006): Medianoche en la historia. Comentarios a las tesis de Walter Benjamin "Sobre el concepto de historia", Madrid, Trotta.

Marx, Karl (2000a): El Capital. Crítica de la economía política, Libro I - Tomo I, Madrid, Akal.
- (2000b): El Capital. Crítica de la economía política, Libro I - Tomo III, Madrid, Akal.

Meikins Wood, Ellen (2003): Empire of Capital, Londres, Verso.

Mertes, Tom (2004): "A Republican Proletariat", New Left Review 30, noviembre-diciembre, pp. 37-47.

Münkler, Herfried (2005): Imperien: Die Logik der Weltherrschaft-vom Alten Rom bis zu den Vereinigten Staaten, Berlín, Rowohlt.

Retort (Boal, lain; Clark, T. J.; Matthews, Joseph; Watts, Michael) (2005): Afflicted Powers. Capital and Spectacle in a New Age of War, Londres, Verso.

Robin, Corey (2007): "Dragon-Slayers", London Review of Books, vol. 29, n. 1 : http://www.lrb.co.uk/v29/n01/ robi02_html

Teschke, Benno (2006): "Imperial Doxa from the Berlin Republic", New Left Review 39, mayo-junio, pp. 128-140.

Zizek, Slavoj (2002): ¿Quién dijo totalitarismo? Cinco intervenciones sobre el (mal)uso de una noción, trad. Antonio Gimeno, Valencia, Pre-textos. 